\title{
MARKETING THE BUILT ENVIRONMENT? THE BUCK STOPS WITH STRATEGIC PLANNING
}

\author{
Deborah Peel ${ }^{1}$ \\ ${ }^{1}$ School of the Built Environment, Faculty of Art, Design and the Built Environment, University of Ulster, \\ Northern Ireland, UK, \\ d.peel@ulster.ac.uk
}

\section{Introduction}

The marketability of the built environment is a contested concept. This paper considers some of the ways in which the idea may be interpreted, designed and implemented. In pragmatic terms, and in the specific context of promoting sustainable economic growth in the UK, the statutory land use planning system has an important role to play in mediating constructions of marketability. In the Scottish Government's (2010: 9, emphasis added) policy statement on nationally important land use planning matters, for example, the Government clearly states that local planning authorities should 'ensure that there is a range and choice of marketable sites and locations for businesses allocated in development plans, including opportunities for mixed use development, to meet anticipated requirements and a variety of size and quality requirements.' This confirms one of the primary pillars of the land use planning system - to use its development plan functions to identify and zone land for an appropriate and diverse mix of uses and users (Millichap, 1991). In providing a degree of certainty to the market and potential investors, the Scottish Government (2010: 9) further details that: 'Marketable land should meet business requirements, be serviced or serviceable within 5 years, be accessible by walking, cycling and public transport, and have a secure planning status.' This list of functional requirements indicates the wider context for the strategic and timely planning of infrastructure and the need to ensure that an appropriate - and sustainable modal share of transport provision is provided. Marketability from this perspective infers a need to be alert to debates around sustainability and the requirement to promote development in sustainable locations, particularly in terms of public transport accessibility, and healthier modes of travel. This focus also involves strategic planning so as to provide access to an integrated road and rail network. In addition, the Scottish Government recognises the transport opportunities afforded by water for manufacturing, warehousing and distribution purposes. Perceptions of locational advantage and the availability of the necessary infrastructure are then paramount in terms of the promotion of an individual site's marketability.

Crucially, however, development contexts evolve and the Scottish Government (2010: 9) further states that: 'The supply of marketable sites should be regularly reviewed. New sites should be brought forward where existing allocations do not meet current and anticipated market expectations. Where identified sites are no longer considered appropriate or marketable, they should be reallocated for another use through the development plan.' Here lies a conundrum. The question of market expectations and what is marketable at a given time and place fluctuate. This localised context dependency amidst evolving global economic circumstances raises fundamental questions about the flexibility of a local planning authority to adjust its policies and land allocations in an appropriate way as conditions change (Lovering, 2010). Moreover, a foundational principle of development planning is that the associated decision-making framework for the 
elaboration of the plan is robust, transparent, and open. A core tenet of the UK statutory land use planning system is that the development plan framework, and decisions pertaining to individual planning applications, is participative and democratic, and based on appropriate consultation and community engagement. Commercial development concerns are thus subject to professional judgements, statutory consultation, and public acceptability. Revisions to a development plan need to be taken in adherence to these requirements.

\section{The Marketability of Place}

A related but different scalar aspect of contemporary debates exists around the marketability of individual places and the notion of a marketable urbanism (Bourke, 2010). This idea takes the notion of the marketable built environment to a different level since it involves the active marshalling of different public, private and civic interests in a collective endeavour to market a shared environment. The logic of a marketable built environment suggests that individual commercial interests must be subsumed in support of a united and marketable image of the wider built environment as opposed to individual elements. Three examples are used to illustrate some of the issues and challenges involved.

First, the introduction of Business Improvement Districts as an institutional, contractualised mechanism to coordinate commercial interests in a delineated area is indicative of contemporary attempts to lever in additional funding and engender a collective concern with respect to an identifiable business environment (Peel et al., 2009). Though designed specifically to address locally agreed priorities, Business Improvement Districts generally include measures to enhance the physical environment, improve safety, offer additional activities and attractions to those provided by the local authority, and augment the visibility and profile of a defined area. In other words, an important feature of Business Improvement Districts is to strengthen the marketability of the built environment and the services it supports. This is, in effect, the maintenance of urban vitality and viability through deliberate collective action (Lloyd \& Peel, 2007). Nevertheless, the creation of a Business Improvement District is predicated on a ballot to secure the engagement of the majority of the businesses falling within the defined area and the payment of an additional levy. Support for this form of collective action requires mobilisation and persuasion in order to bring all the interests on board. In essence, the marketability of the wider built environment is dependent upon securing and sustaining cooperative commitment by individual - and potentially inherently competitive - private interests.

Second, in the context of a spectrum of cultural regeneration strategies and initiatives, the marketability of the built environment may also be linked to the ability of local authorities to market their town or city in ways that differentiate it from its competitors (Bourke, 2010). Nonetheless, what might be termed the collision of art and economy has, as Garcia (2004: 314), for example, argued 'shifted traditional notions of culture as art and heritage to a view of culture as an economic asset, a commodity with market value and, as such, a valuable producer of marketable city spaces'. This, she explained, raises concerns with respect to the potential commodification of culture and the prioritisation of certain cultures over others. Such tensions are illustrative of the risks involved in a reductionist approach to the marketing or branding of the built environment and adopting a vision which fails to accommodate the essential complexity of individual places and the differentiated and lived ways in which cities are experienced. Moreover, in an attempt to create and communicate an image which may be understood by a range of different global audiences, local and culturally specific identities risk being subsumed into relatively more universalised narratives. Although the idea that cities can be marketed as 
products is contested (Kavaratzis \& Ashworth, 2006), the notion that urban centres can be packaged and sold is not new (Ashworth \& Voogd, 1994). In tracing the development of the use of cultural strategies and urban policy, Garcia (2004) highlighted, however, that interest in city marketing and branding techniques by city authorities is growing. Yet, in an increasingly globalised competitive milieu, an ability to differentiate the built environment has prompted a concern with what Bourke (2010: 91) terms the challenge of generating a 'marketable identity and brand resonance'. The marketable built environment may thus be elusive in practice.

Finally, and notwithstanding the concerns about the marketability of the built environment, the branding and marketing of cities is acknowledged as a sophisticated activity with increasing relevance for the planning, development and management of the built environment (Lloyd \& Peel, 2007). Given the prevalence of place marketing activities, it is then important for built environment professionals to take cognisance of the representational aspects of policy making to complement the relatively more functional and physical aspects involved in the design and management of the built environment. Following Karavatzis (2004), there are four inter-related aspects to take into consideration. The first is concerned with the urban landscape, the available green spaces, the layout and ongoing management of the built environment, and the use of urban design. The overall configuration of the landscape communicates a particular story about the built environment. Second, Karavatzis (2004) argues that the selection and implementation of particular infrastructure projects or facilities can affect the marketability of an area, by restricting or enhancing accessibility to and from - or within - a city. The commitment to a major infrastructure project, such as the new light rail scheme in Kuala Lumpur under the Economic Transformation Programme (MY Rapid Transit, 2011), for example, is illustrative of attempts to market Kuala Lumpur as one of the top twenty most liveable and economically-vibrant cities in the world. Third, according to Karavatzis (2004), the nature of the structure of the governance arrangements can influence the perceived marketability of the built environment since how a city is governed can impact perceptions of how a place is managed in positive or negative ways. This observation is important because it highlights that the marketability of the built environment is more than the physical components; it embraces institutional and organisational elements (North, 1990). Finally, there are a number of related behavioural dimensions involved in deliberate processes of place-marketing (Karavatzis, 2004). These aspects might include leadership styles, approaches to budgeting, methods for engaging local communities, or how service priorities are identified. Taken, together this synthesis of four inter-related dimensions - landscape, infrastructure, institutional structure and behaviour - affords a relatively more complex appreciation of the marketability of the built environment which layers institutional dimensions onto the physical fabric.

\section{The Buck Stops Here}

Marketability is not solely a concern of the private sector. Given the statutory parameters of the land use planning system, however, the relative flexibility and responsiveness to the needs of commercial interests as market conditions change must be tempered by the collation and interpretation of material evidence, and the judicious weighting of competing policy priorities by city planners. The nature of government intervention can nonetheless influence marketability. For example, if derelict listed buildingsare to be brought back into active use, local authorities have a responsibility actively to enable development, unlock the potential of heritage sites, articulate economic viability, and create market value (English Heritage, 2008). Moreover, how public sector strategies, funds, and incentives are deployed in order to enhance the marketability of brownfield land, that is, 
sites where investment may be hard to attract due to the existence of hazardous substances, pollutants, or contaminants, will be critical if private sector investment and spatially just outcomes are to be secured (McCarthy, 2009). In effect, governments must be adept at articulating the marketability of the built environment if heritage sites or brownfield locations, for example, are to attract investment. In addition, perceptions of market viability will involve governments detailing economically efficient solutions. How successful public authorities are in this activity will determine their ability to secure social, cultural, and environmental benefits. Critically, the planning system is designed to operate in the public interest and to manage the development and use of a finite land resource over short-, medium- and longer time-frames. The future marketability of the built environment depends then on how land use and development are planned and managed in the immediate term. From this perspective, the (future) marketability of the built environment may be considered as something to be protected now. It is essential that hasty decisions to respond to current market expectations do not jeopardise future market needs, prospects, and priorities. In other words, the buck stops with strategic planning.

\section{References}

Ashworth, G.J. \& Voogd, H. (1994). Marketing and place promotion, in J. R. Gold \& S. Ward, (Eds), Place Promotion: The Use of Publicity and Marketing to Sell Towns and Regions, Chichester: John Wiley, 39-52.

Bourke, A.G. (2010). Becoming European? Constructing Identity in Urban Regeneration Discourse in Ireland, Formations, 1 (1): 81-102.

English Heritage (2008). Enabling Development and the Conservation of Significant Places. Policy and Guidance. London: English Heritage.

Garcia, B. (2004). Cultural Policy and Urban Regeneration in Western European Cities: Lessons from Experience, Prospects for the Future, Local Economy, 19 (4): 312-326.

Kavaratzis, M. (2004). From city marketing to city branding: towards a theoretical framework for developing city brands, Place Branding and Public Diplomacy, 1, 58-73.

Kavaratzis, M. \& Ashworth, G.J. (2006). City branding: an effective assertion of identity or a transitory marketing trick?, Place Branding and Public Diplomacy, 2, 183-94.

Lloyd, M.G. \& Peel, D. (2007). In Search of a Small City's Élan Vital. Inverness: Towards Progressive Change?' Town Planning Review, 78 (6): 749-773.

Lovering, J. (2010). Will the Recession Prove to be a Turning Point in Planning and Urban Development Thinking?, International Planning Studies, 15 (3), 227-43.

McCarthy, L. (2009). Off the Mark? Efficiency in Targeting the Most Marketable Sites Rather Than Equity in Public Assistance for Brownfield Redevelopment, Economic Development Quarterly, 23 (3), 211-228.

Millichap, D. (1991). The Effective Enforcement of Planning Controls. London: Butterworths.

MY Rapid Transit (2011). 'MY Rapid Transit Heralds a New Era for Malaysia's Public Transport System', Media Release. Available at: http://kvmrt.com.my/pdf/08072011.1.pdf [Last accessed: 20 December 2011]

North, D.C. (1990). Institutions, Institutional Change and Economic Performance, Cambridge: Cambridge University Press. 
Peel, D. \& Lloyd, M.G. (2008). New Communicative Challenges: Dundee, Place branding and the reconstruction of a city-image, Town Planning Review, 79 (5): 507-532.

Peel, D. Lloyd, M.G. \& Lord, A. (2009). Business Improvement Districts and the Discourse of Contractualism, European Planning Studies, 17 (3): 401-422.

Scottish Government (2010). Scottish Planning Policy, Edinburgh: Scottish Government. 